\title{
Escrevivência de Conceição Evaristo: el compromiso de la literatura con la vida y viceversa*
}

\author{
Paola María Marugán Ricart
}

Conceição Evaristo es una de las autoras más destacadas de la literatura (afro) brasileña ${ }^{1}$ contemporánea. Su escritura-vivencia pertenece a un matrilinaje ancestral encabezado por grandes contadoras de historias como Carolina Maria de Jesús y Maria Firmina dos Reis. Se trata de una extensa producción literaria comprometida con rescatar las memorias del Atlántico negro y los relatos de vida del periodo esclavista, para pensar las violencias estructurales del presente, sobre las cuales se constituyó la nación brasileña. La publicación es una compilación de textos de escritoras e investigadoras del país, dedicada a analizar la noción de escrevivência, creada por Conceição Evaristo durante su investigación de maestría a mediados de la década de 1990. Esta iniciativa colectiva es resultado del proyecto "Memórias e Escrevivência”2 (2018), organizado por Itaú Social, cuyo propósito fue aunar una serie de análisis, vivencias y afectos que comprendieran el sentido de escrevivência: un marco epistemológico y metodológico para la creación literaria e incluso de producción de vida.

* Reseña del libro de Constância Lima Duarte e Isabella Rosada Nunes (orgs.), Escrevivência: a escrita de nós. Reflexóes sobre a obra de Conceição Evaristo, Río de Janeiro, Mina Comunicação e Arte, 2020.

${ }^{1}$ Conceição Evaristo a menudo es considerada una de las grandes referencias de la literatura afrobrasileńa, dado que como mujer negra, sus escrituras y vivencias remiten a las condiciones de ese lugar de enunciación. Sin embargo, he preferido dejar el prefijo afro- entre paréntesis por considerar que la relevancia de su obra excede los límites del marcador racial "literatura afro". Como ella misma ha señalado en reiteradas ocasiones, su obra tiene una dimensión diaspórica y universal, que permite el reconocimiento de la humanidad de sus personajes, sea cual sea la localización del sujeto-lectorx.

${ }^{2}$ El proyecto consistía en un conjunto de talleres y conferencias dirigidos por la misma autora, con el objetivo de reflexionar sobre la práctica escritural, el lugar de enunciación del sujeto-narrador y la dimensión política de la producción de memoria en el campo literario. 
El libro se organiza en torno a trece capítulos de diferentes autorías y una introducción a cargo de una de las organizadoras de este proyecto. Además cuenta con la intervención artística de Goya Lopes, quien recrea visualmente la belleza del imaginario que la obra de Conceição Evaristo trae consigo y asimismo, introduce elementos del universo mito-poético de las tradiciones afrodescendientes en territorio brasileńo. La riqueza del concepto escrevivência ha desplegado distintas líneas temáticas abordadas en esta compilación, resumidas en los siguientes puntos: i) la íntima relación entre las experiencias de vida y la producción literaria; ii) la creación de los múltiples sentidos de dicho concepto, en los procesos de creación de la propia autora y en diálogo con escritorxs negrxs del Caribe y Norteamérica; iii) escrevivência concebida como una práctica narrativa afrodiaspórica, cuyos vasos comunicantes se encuentran entre el quilombolismo, el saber sankofa y la filosofía africana ubuntuista; iv) reflexiones en torno a escrevivência como un concepto identitario, capaz de producir ciertos patrones en aquello considerado "literatura afrobrasileña"; $v$ ) debates acerca de los estereotipos y estigmas que determinan las masculinidades negras en la obra de Conceição Evaristo; vi) análisis del término escrevivência concebido como un acervo de relatos y vidas (palabras-experiencia; memoriaagua) puestos en circulación, gracias a la riqueza analítica y política de dicho término; vii) escrevivência propone una metodología de investigación feminista, antirracista y anticolonial, una ruta de escritura académica militante y por ende, un posicionamiento ético en los procesos de producción de conocimiento.

La publicación además incluye dos textos de la propia autora en los que presenta la "geografía afectiva" - según sus palabras- de la cual surgió dicha categoría, un territorio de memorias enmarañadas, cuya génesis se remonta a las historias que la escritora escuchaba en su infancia entre las mujeres de su familia. ¿Es necesario comprometer la vida con la escritura? O por el contrario, ¿la escritura con la vida? -se pregunta Conceição Evaristo. Estos interrogantes fueron articulándose a partir de una precoz toma de conciencia política, frente a las precariedades de la vida del sujeto-mujer negra de la favela donde pasó su niñez en Minas Gerais. El diptongo escritura y vivencia del propio término informa acerca de un marco de prácticas escriturales profundamente comprometido con las experiencias de la narradora, el que sin embargo excede las fronteras de la escritura de sí puesto que también elabora narrativas basadas en las experiencias de vida del grupo social al que dicho sujeto pertenece (el lugar de fala -según Djamila Ribeiro $\left.(2017)^{3}\right)$, así como en una memoria colectiva ancestral, enraizada en la herida todavía sangrante de los tiempos de la esclavitud.

${ }^{3}$ Djamila Ribeiro (2017) afirma que el lugar de enunciación de cada sujeto no remite a la localización individual de cada uno, sino más bien al grupo social de pertenencia. 
La escrevivência se asienta en los tres elementos básicos de una producción de conocimiento afrocentrada y afrodiaspórica: la oralidad, la ancestralidad y la pluritemporalidad. En este sentido, el campo de creación que inaugura el término puede concebirse como una praxis quilombolista (entendiendo el quilombo como un foco de resistencia cultural), comprometida con el (re) existir del cuerpo negro. Asimismo, la propuesta de que la escrevivência, como una práctica del narrar contra-hegemónico, implica considerar la literatura "un lugar de expurgación personal y colectiva" (Sousa e Silva en Lima Duarte; Rosada Nunes, 2020:115) y en este sentido, afirma la autora, "nuestra escrevivência no es para adormecer a los de la Casa-Grande y sí para despertarlos de sus sueños injustos" (Evaristo, 2020:30). Por último, escrevivência conforma un archivo de historias, sueños y vidas, además de un principio teórico y metodológico para la producción, circulación y almacenamiento de narrativas (Borges en Lima Duarte; Rosada Nunes, 2020), cuyos trazos genealógicos caminan entre los "quilombos urbanos" contemporáneos -según Beatriz Nascimento-, como las escuelas de samba, el carnaval o los terreiros de Candomblé ${ }^{4}$ y las estrategias de resistencia cultural y política de los asentamientos quilombolas durante el periodo colonial.

Escrevivência, principio metodológico, teórico y ontológico que apuesta por contribuir a los procesos de "reparación epistemológica" en el marco de la producción académica brasileña, sometida desde su instauración a las relaciones de poder de la colonialidad del saber. Escrevivência, práctica discursiva que posibilita la descodificación de "los elementos tradicionales de la praxis textual" y "concede fluidez a la autoría discente frente a las producciones académicas tradicionales” (Felisberto en Lima Duarte; Rosada Nunes, 2020:172), reforzando aquellos lugares de fala que todavía habitan espacios de subalternidad y generando rutas teóricas alternativas de mayor creatividad y originalidad, que aprecien los saberes intuitivos no reconocidos por el positivismo científico occidental. No cabe duda de que la riqueza conceptual, discursiva e incluso metodológica que ha devenido del concepto de Conceição Evaristo queda recogida en esta publicación la cual, sin lugar a duda, es un referente obligado en el mundo de las luchas descoloniales, antirracistas y feministas del Sur.

Según la autora, cualquiera podría analizar experiencias de racismo -por ejemplo-siempre y cuando se haga desde la conciencia responsable de saber el lugar que ocupa el grupo social de origen, en las intersecciones de las matrices de opresión y privilegios constitutivas de la subjetividad hablante.

${ }^{4}$ El Candomblé es una religión brasileña de matriz africana y los terreiros son los espacios de culto, en los que las personas se reúnen para la realización de proyectos de carácter social y pedagógico, no sólo para llevar a cabo sus prácticas religiosas y espirituales. 


\section{P.M. MARUGÁN RICART ESCREVIVÊNCIA DE CONCEIÇÃO EVARISTO}

\section{REFERENCIAS}

Filme Ôrí, dirección Raquel Gerber, guión Beatriz Nascimento, 1989, color, 80’.

Ribeiro, Djamila (2017). O que é o lugar de fala? Belo Horizonte: Editora Letramento. 


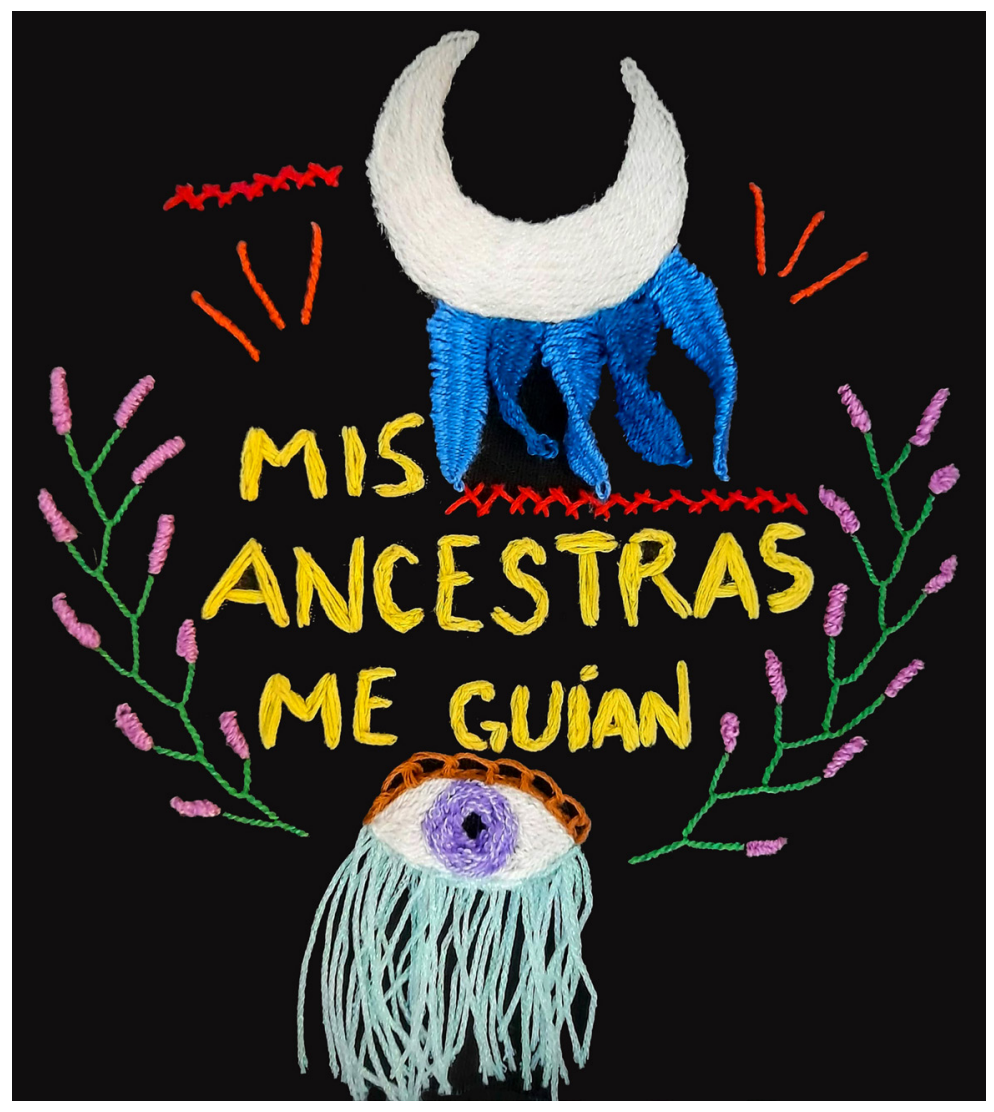

Las ancestras en mis ojos, mi lengua y mis pies 
Alejandra Collado | Las voces de las ancestras

Bordado en tela

Agosto de 2021 